\title{
Perancangan Sistem Smart Home Dengan Konsep Internet Of Things Hybrid Berbasis Protokol Message Queuing Telemetry Transport
}

\author{
Yohanes Bowo Widodo ${ }^{*}$ ), Ade Muhammad Ichsan ${ }^{2)}$, Tata Sutabri ${ }^{3)}$ \\ 1)2) Program Studi Teknik Informatika, Universitas Mohammad Husni Thamrin \\ ${ }^{3)}$ Program Studi Sistem Informasi, Universitas Respati Indonesia \\ ${ }^{*}$ Correspondence Author: ybowowidodo@gmail.com, Jakarta, Indonesia \\ DOI: https://doi.org/10.37012/jtik.v6i2.302
}

\begin{abstract}
Abstrak
Penelitian ini bertujuan untuk memberikan rasa kenyamanan, keamanan dan efisiensi bagi user atau pemilik rumah dalam mengendalikan dan memonitoring peralatan elektronik yang digunakan dirumah dengan pemanfaatan teknologi smartphone dan koneksi internet agar dapat melakukan pengendalian dari jarak jauh. Dengan tujuan tersebut, maka dibuatlah perancangan sistem Smarthome dengan konsep Internet of Things Hybrid berbasis Protokol Message Queuing Telemetry Transport (MQTT).

Pada penelitian ini, dikembangkan suatu sistem User interface yang terdiri dari aplikasi berbasis android yang terhubung dengan aplikasi google assistant. Sistem ini menggunakan protokol MQTT karena menggunakan energi yang sangat sedikit dibandingkan dengan protokol lainnya, dan dapat bekerja dengan baik di dalam lingkungan yang memiliki bandwidth rendah dan latency yang tinggi.

Untuk mengevaluasi performa dari sistem ini, dilakukan pengujian dengan menggunakan metode prototyping yang terhubung dengan aplikasi berbasis android dan terintegrasi dengan aplikasi google assistant. Dari hasil pengujian yang telah dilakukan, sistem ini dapat dikendalikan dari jarak jauh menggunakan perintah tombol maupun perintah suara dan dapat berfungsi sebagaimana dengan tujuan awal penelitian ini.
\end{abstract}

Kata Kunci : Smarthome, Internet, MQTT, Android, Google Assistant

\begin{abstract}
This study aims to provide a sense of comfort, safety and efficiency for users or home owners in controlling and monitoring electronic equipment used at home by utilizing smartphone technology and internet connection in order to control remotely. With this aim, a smarthome system design was made with the concept of Internet of Things Hybrid based on the Message Queuing Telemetry Transport (MQTT) Protocol. In this study, a user interface system was developed which consists of an android-based application that is connected to the google assistant application. This system uses the MQTT protocol because it uses very little energy compared to other protocols, and can perform well in environments with low bandwidth and high latency.

To evaluate the performance of this system, testing is carried out using the prototyping method that is connected to an Android-based application and is integrated with the Google Assistant application. From the results of tests that have been carried out, this system can be controlled remotely using button commands or voice commands and can function as intended for this study.
\end{abstract}

Keywords: Smarthome, Internet, MQTT, Android, Google Assistant

\section{PENDAHULUAN}

Internet menjadi salah satu kebutuhan wajib untuk manusia saat ini, karena segalanya kini berhubungan dengan internet. Bukan hanya untuk hiburan, internet juga kini bisa digunakan menjadi salah satu media pembelajaran, pekerjaan dan banyak hal lainnya. Dengan kebutuhan yang semakin kompleks dan internet mempermudah semua hal itu, 
maka internet menjadi kebutuhan manusia saat ini. Dengan adanya teknologi internet, kini manusia semakin kaya akan informasi. Banyak manfaat dari internet terutama dalam bidang Komunikasi dan Informasi.

Berbicara mengenai perkembangan dari internet, ada salah satu bagian dari perkembangan di dunia internet yaitu Internet of Things (IoT). Secara singkat Internet of Things adalah teknologi di mana benda-benda di sekitar kita dapat berkomunikasi antara satu sama lain melalui sebuah jaringan Internet. Jadi Internet of Things (IoT) adalah sebuah konsep dimana suatu objek memiliki kemampuan untuk mentransfer data melalui jaringan internet. Dan salah satu pendukung perkembangan teknologi IoT itu sendiri adalah munculnya protokol MQTT (Message Queuing Telemetry Transport). Protokol MQTT (Message Queuing Telemetry Transport) adalah protokol yang berjalan pada diatas stack TCP/IP dan mempunyai ukuran paket data dengan low overhead yang kecil (minimum 2 bytes) sehingga berefek pada konsumsi catu daya yang juga cukup kecil. MQTT dirasa tepat untuk menjadi protokol IoT karena MQTT bersifat light weighted message dan didesain untuk perangkat yang memiliki sumber daya terbatas.

Dengan perkembangan teknologi saat ini yang telah merambah ke dalam kehidupan manusia, dan salah satu pemanfaatan teknologi itu sendiri seperti adanya pengembangan aplikasi rumah pintar (SmartHome) yang dapat memberikan kenyamanan, keamanan, dan efisiensi bagi pengguna. Dengan pemanfaatan smartphone dan koneksi internet, kita dapat melakukan pengendalian jarak jauh terhadap berbagai macam alat-alat elektonik yang terdapat pada rumah kita seperti lampu, kipas angin, air conditioner (AC) bahkan kunci pada pintu rumah sekalipun. Pengendalian jarak jauh merupakan pengendalian yang sangat dibutuhkan mengingat efisiensi yang di peroleh dari pengendalian jarak jauh. Sebagai manusia biasa tentunya kita tidak luput dari yang namanya sifat pelupa. Terkadang kita lupa untuk mematikan lampu atau tidak merasa yakin bahwa kita telah mengunci pintu rumah ketika sedang berpergian atau sedang beraktifitas diluar rumah sehingga kita harus kembali kerumah dan melakukan pengecekan kembali yang tentunya sangat tidak efisien baik dari sisi waktu maupun finansial seperti penggunaan biaya transportasi umum atau penggunaan bahan bakar untuk kendaraan yang dibutuhkan untuk kembali kerumah. Dengan tujuan efisiensi itulah maka muncul ide Perancangan Sistem Smarthome Dengan Konsep Internet of Things Hybrid Berbasis Protokol Message Queuing Telemetry Transport agar pemilik rumah dapat melakukan kontrol jarak jauh menggunakan aplikasi pada smartphone Android dan perintah suara menggunakan Google Voice Assistant.

Adapun penelitian terdahulu yang digunakan sebagai acuan dalam penelitian ini adalah pertama, penelitian dengan judul Voice Controlled Home Automation System 
Menggunakan Mikrokontroller Wemos (Prakoso, 2018). Kedua, Penelitian dengan judul Implementasi MQTT Protocol Pada Smart Home Security Berbasis WEB (Susanto, et al., 2018). Ketiga, Penelitian dengan judul Perancangan Sistem Kendali Otomatis Pada Smart Home Menggunakan Modul Arduino Uno (Kurnianto, et al., 2016). Keempat, Penelitian dengan judul Prototype Smart Home Dengan Konsep Internet of Things (IOT) Menggunakan Arduino Berbasis WEB (Hakim, 2015). Kelima, Penelitian dengan judul Perancangan Prototype Smart Home System Berbasis Mikrokontroler Arduino Menggunakan Bluetooth (Susanto, 2018).

Perbedaan penelitian sekarang dengan penelitian sebelumnya yaitu beberapa penelitian masih dibuat berbasis web ataupun menggunakan konektifitas Bluetooth dan masih terbatasnya fitur yang tersedia.

Smart Home atau Rumah Pintar adalah bagian dari inovasi IoT (Internet of Things), di mana seluruh benda atau perabotan sehari-hari "dibuat menjadi pintar" karena integrasi teknologi didalam bentuk chip serba bisa. Smart Home atau Smart House (Rumah Pintar) adalah istilah yang biasa dipakai untuk membuat tempat tinggal yang mempunyai peralatan, pencahayaan, pemanas, pendingin ruangan, TV, komputer, sistem audio \& video hiburan, keamanan, dan juga sistem kamera bisa berkomunikasi satu sama lain dan bisa dikendalikan dari jarak jauh. Pengendalian peralatan di tempat tinggal dapat dilakukan dari jarak yang jauh melalui smarthphone atau internet. Teknologi Smart Home ini memungkinkan pemilik tempat tinggal bisa mengontrol keamanan rumahnya dengan menggunakan satu alat saja.

Menurut Wikipedia, Internet of Things, atau dikenal juga dengan singkatan (IoT) merupakan sebuah konsep yang bertujuan untuk memperluas manfaat dari konektivitas internet yang tersambung secara terus-menerus. Adapun kemampuan seperti berbagi data, remote control, dan sebagainya, termasuk juga pada benda di dunia nyata. Sedangkan menurut Casagras (Coordination and support action for global RFID-related activities and standardisation) Mendefinisakan Internet of Things, sebagai sebuah infrastruktur jaringan global, yang menghubungkan benda-benda fisik dan virtual melalui eksploitasi data capture dan kemampuan komunikasi. Infrastruktur terdiri dari jaringan yang telah ada dan internet berikut pengembangan jaringannya. Semua ini akan menawarkan identifikasi objek, sensor dan kemampuan koneksi sebagai dasar untuk pengembangan layanan dan aplikasi kooperatif yang independen. Ia juga ditandai dengan tingkat otonom data capture yang tinggi, event transfer, konektivitas jaringan dan interoperabilitas.

Protokol MQTT (Message Queuing Telemetry Transport) adalah protokol yang berjalan pada diatas stack TCP/IP dan mempunyai ukuran paket data dengan low overhead yang 
kecil (minimum 2 bytes) sehingga berefek pada konsumsi catu daya yang juga cukup kecil, sehingga dapat bekerja di dalam lingkungan yang terbatas sumber dayanya seperti kecilnya bandwidth dan terbatasnya sumber daya listrik, selain itu protokol ini juga menjamin terkiriminya semua pesan walaupun koneksi terputus. Sementara, protokol MQTT menggunakan metode publish/subscribe untuk metode komunikasinya. Publish/subscribe sendiri adalah sebuah pola pertukaran pesan di dalam komunikasi jaringan dimana pengirim data disebut publisher dan penerima data disebut dengan subscriber, metode publish/subscribe memiliki beberapa kelebihan salah satunya yaitu loose coupling atau decouple dimana antara publisher dan subscriber tidak saling mengetahui keberadaannya.

Terdapat 3 buah decoupling yaitu time decoupling, space decoupling dan synchronization decoupling, time decoupling adalah sebuah kondisi dimana publisher dan subscriber tidak harus saling aktif pada waktu yang sama, space decoupling adalah dimana publisher dan subscriber aktif di waktu yang sama akan tetepi antara publisher dan subscriber tidak saling mengetahui keberadaan dan identitas satu sama lain, dan yang terakhir adalah synchronization decoupling kondisi dimana pengaturan event baik itu penerimaan atau pengiriman pesan di sebuah node tidak saling mengganggu satu sama lain (Adi, et al.,2016).

\section{METODE}

Penelitian ini akan membuat suatu sistem yang dapat mengendalikan dan memonitor beberapa peralatan elektronik melalui kontrol jarak jauh dengan memanfaatkan teknologi mikrokontroler yang terkoneksi dengan internet serta beberapa sensor dan modul pendukung. Perancangan sistem ini dibuat untuk memberikan kemudahan bagi user atau penghuni rumah agar dapat mengendalikan serta memonitor peralatan elektronik melalui kontrol jarak jauh.

Penelitian ini meliputi beberapa tahapan sebagai berikut, (1) melakukan suatu pengamatan secara langsung terhadap sebuah rumah yang belum menggunakan aplikasi smarthome. Kemudian menentukan sistem apa yang dibutuhkan untuk memecahkan permasalahan yang ada yaitu bagaimana cara mengontrol dan memonitor segala peralatan elektronik yang ada dirumah melalui kontrol jarak jauh. (2) Mempelajari teknik-teknik dan aspek yang ada pada penelitian-penelitian sebelumnya maupun dari jurnal-jurnal ilmiah baik dalam negeri maupun luar negeri dan dari beberapa buku serta e-book. (3) Melakukan penelitian dengan menggunakan software dan hardware yang dirancang kinerjanya, lalu dilakukan pengujian terhadap aplikasi. Setelah itu aplikasi akan dianalisa, apakah sudah sesuai dengan kebutuhan belum. Jika sudah sesuai dengan kebutuhan maka akan 
disimpulkan hasil yang didapatkan. Jika belum, dilakukan evaluasi guna mencapai hasil akhir yang sesuai dengan rancangan awal penelitian.

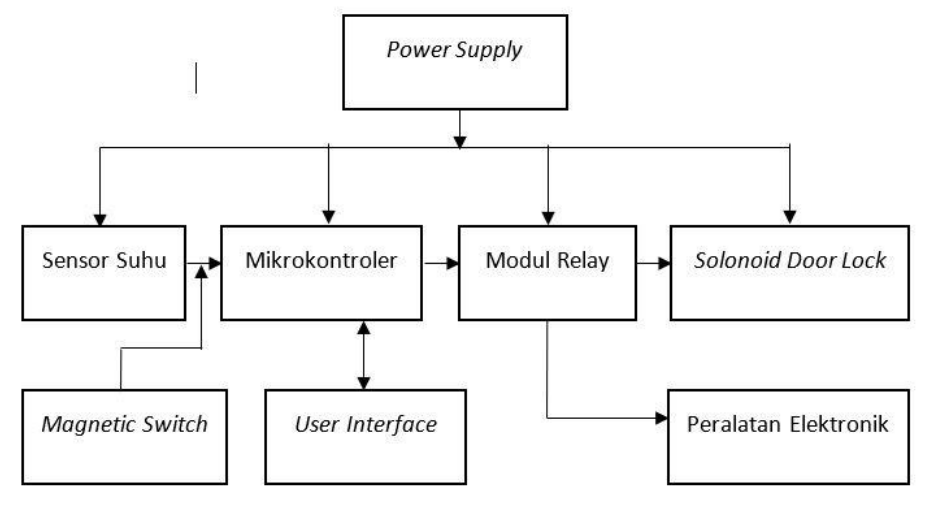

GAMBAR 1. Blok Diagram Sistem Smart Home

Keterangan blok diagram:

1. Power Supply sebagai sumber tegangan DC $12 \mathrm{~V}$.

2. Sensor suhu dan kelembapan udara DHT-11 untuk mendeteksi kondisi suhu dan kelembaban udara didalam suatu ruangan.

3. Mikrokontroler sebagai penerima data dari sensor suhu dan Magnetic Switch, memproses data dan mengirimkan data kepada Relay serta Solonoid Door Lock.

4. Magnetic Switch berfungsi sebagai sensor pengaman pada pintu dan jendela rumah.

5. Modul Relay digunakan untuk mengaktifkan dan menonaktifkan Solonoid Door Lock dan peralatan elektronik lainnya.

6. Solonoid Door Lock adalah sebuah alat yang digunakan untuk mengunci pintu rumah.

7. Peralatan Elektronik seperti lampu, kipas dan sebagainya.

8. User Interface sebagai penghubung antara user dan sistem.

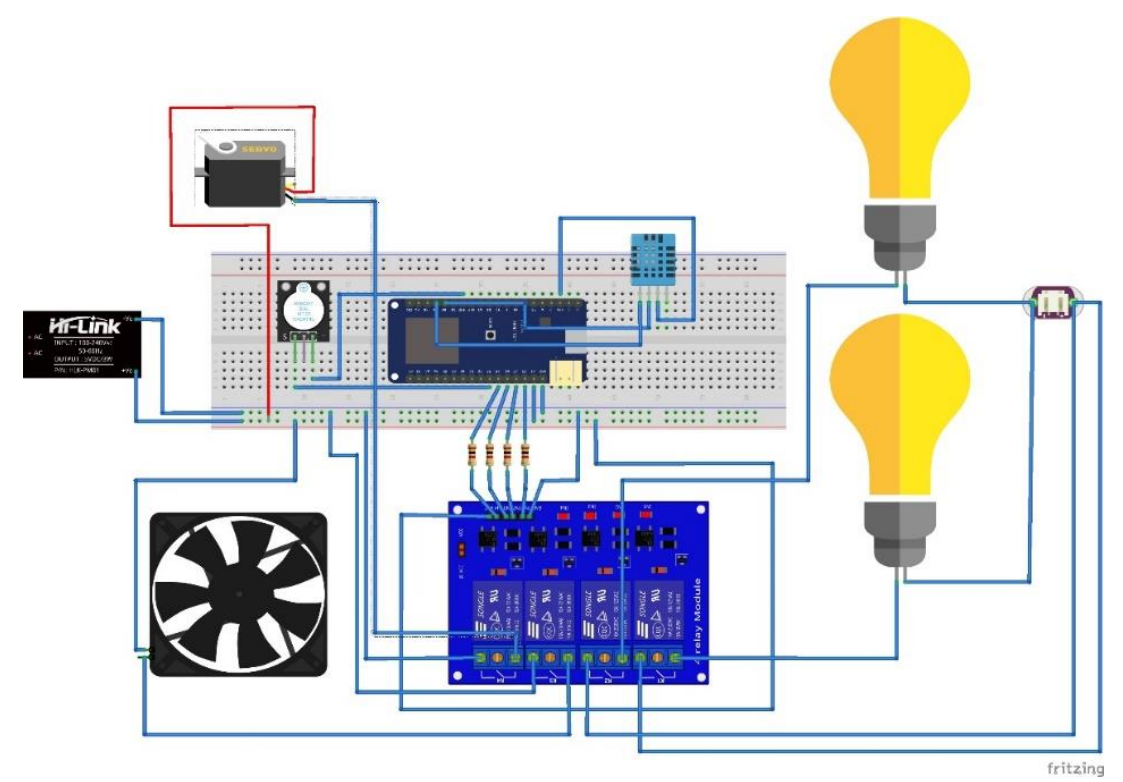

GAMBAR 2. Rancangan Perangkat Keras 
Pengembangan pada perangkat lunak yang diterapkan melalui mikrokontroller ESP-

32. Sistem ini menggunakan bahasa pemrograman $C$ yang diprogram menggunakan software Arduino IDE. Karena Sistem ini dapat dikendalikan melalui kontrol jarak jauh, maka untuk menampung sebuah data aktual yang terjadi seperti data suhu dan kelembaban pada suatu ruangan serta data keadaan aktif atau tidaknya suatu peralatan elektronik yang digunakan, sistem ini menggunakan Cloud Service seperti Adafruit dan IFTTT (If This Than Than) serta menggunakan protokol MQTT (Message Queing Telemetry Transport) sebagai pengirim pesan (Broker) dari mikrokontroler menuju Cloud Service.

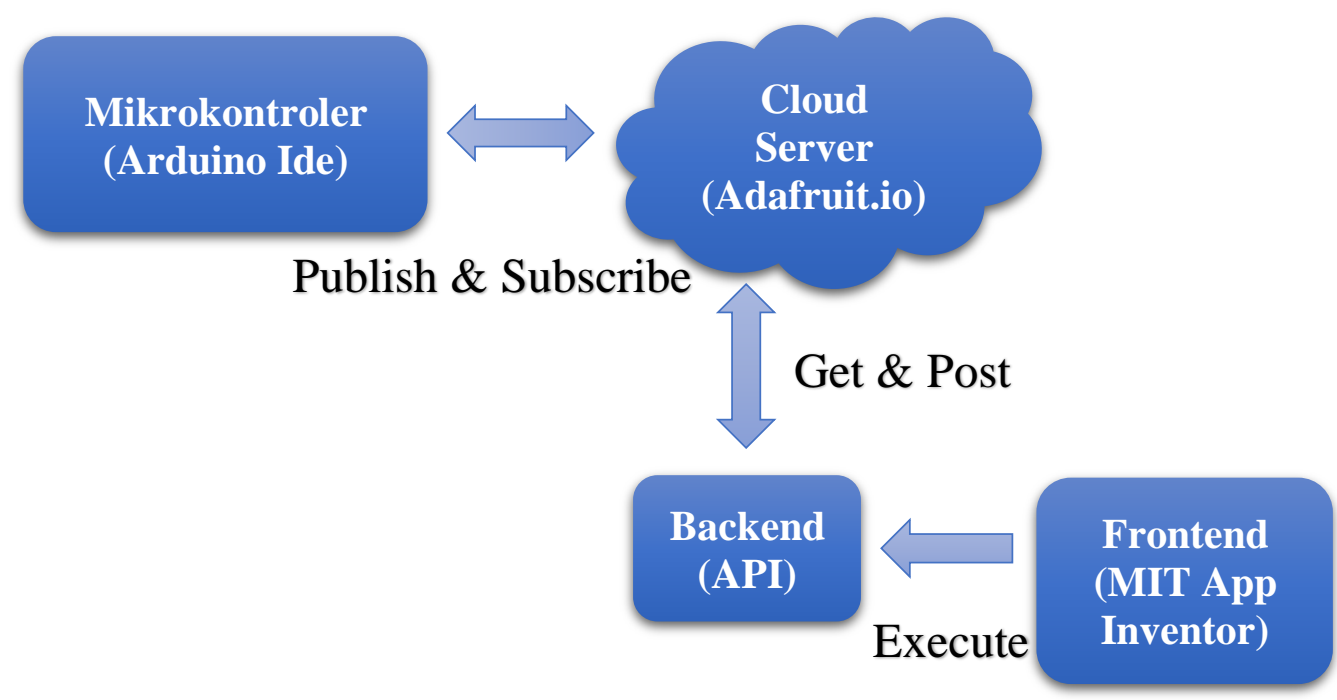

Gambar 3. Rancangan Perangkat Lunak

\section{HASIL DAN PEMBAHASAN}

Pengujian dilakukan untuk mengetahui apakah semua komponen yang akan digunakan seperti sensor ataupun modul-modul pendukung lainnya tidak mengalami masalah ketika terhubung dengan mikrokotroler ataupun mengalami kerusakan saat pembelian komponen tersebut. 


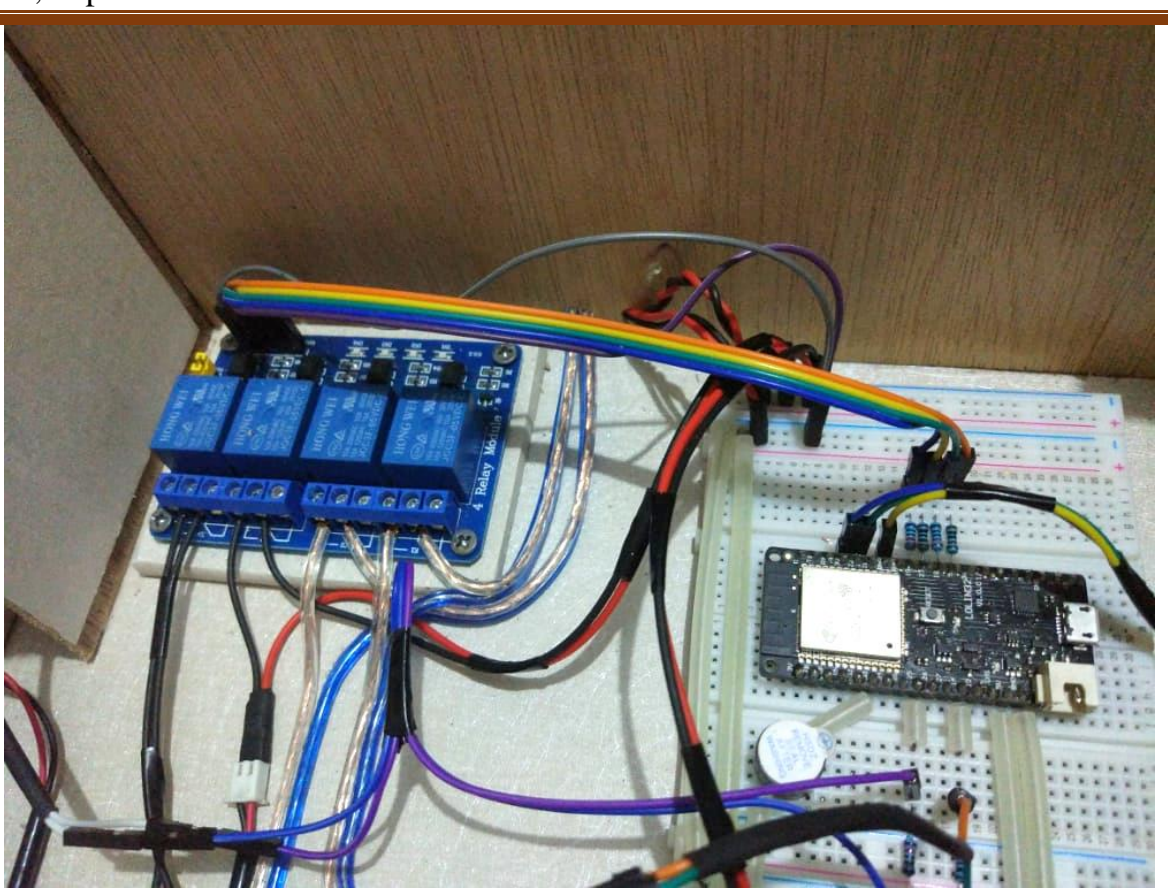

Gambar 4. Rangkaian Relay dengan Mikrokontroler

Rangkaian mikrokontroler dengan Sensor Suhu dan Kelembaban DHT-11 dengan cara menghubungkan keduanya dengan beberapa kabel jumper.

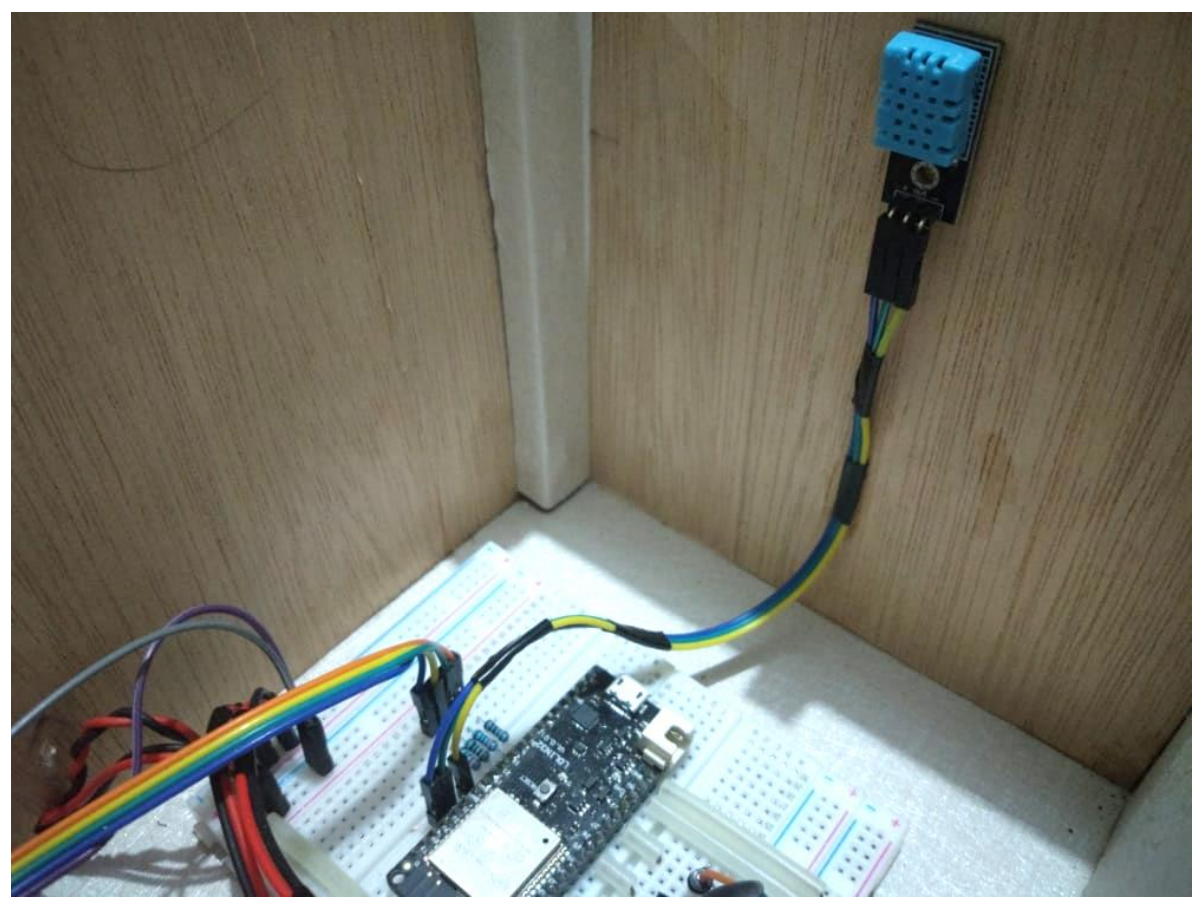

Gambar 5. Rangkaian Sensor DHT-11 Dengan Mikrokontroler 


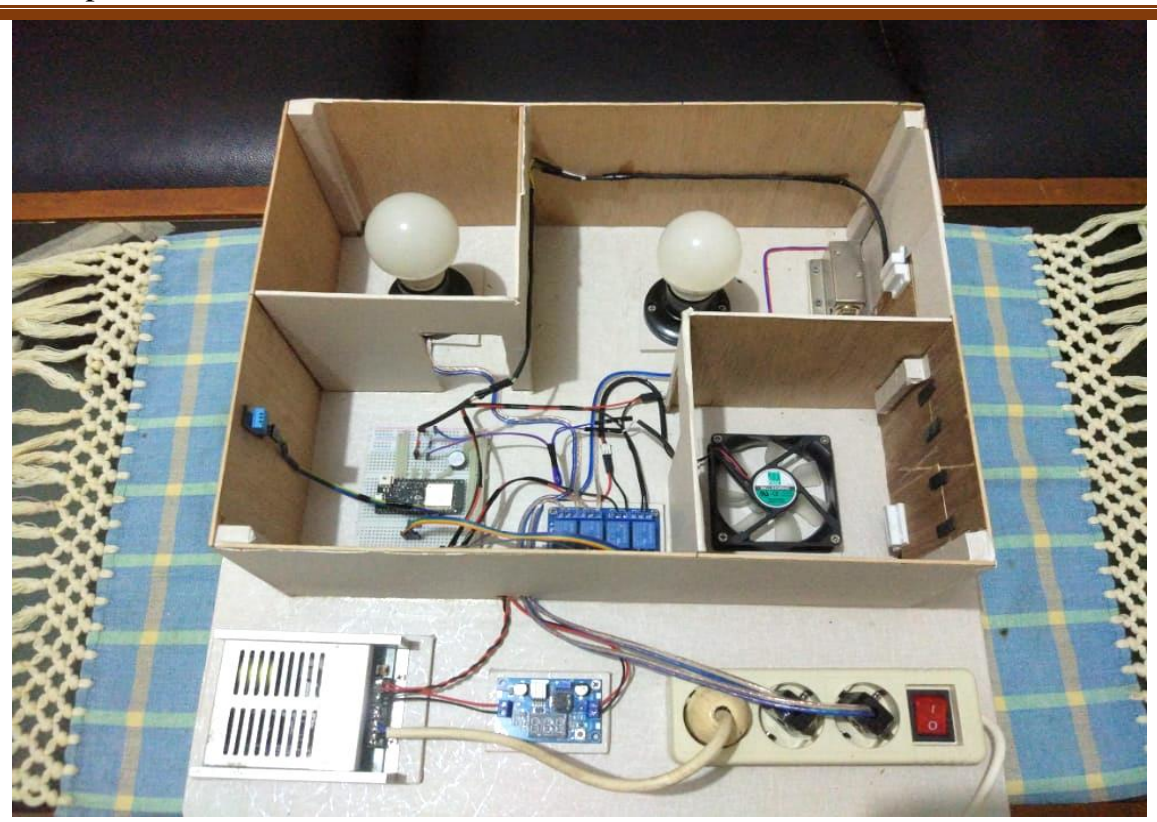

Gambar 6. Rangkaian Prototipe Smarthome dengan Peralatan Elektronik

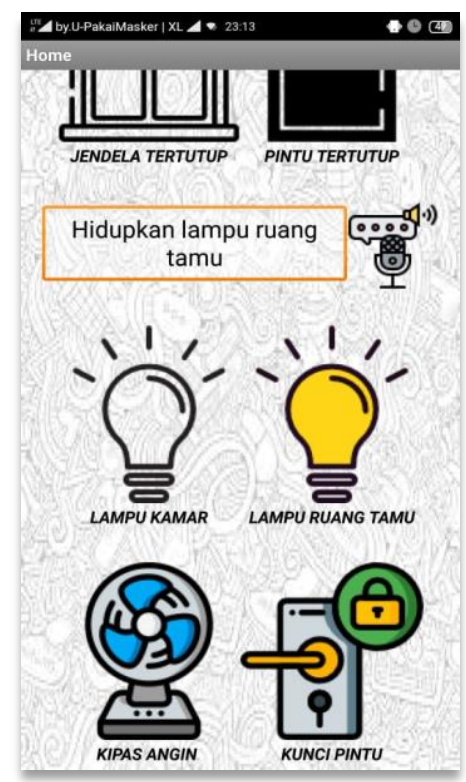

Gambar 7. Tampilan Uji Coba Aplikasi Via Smartphone Android

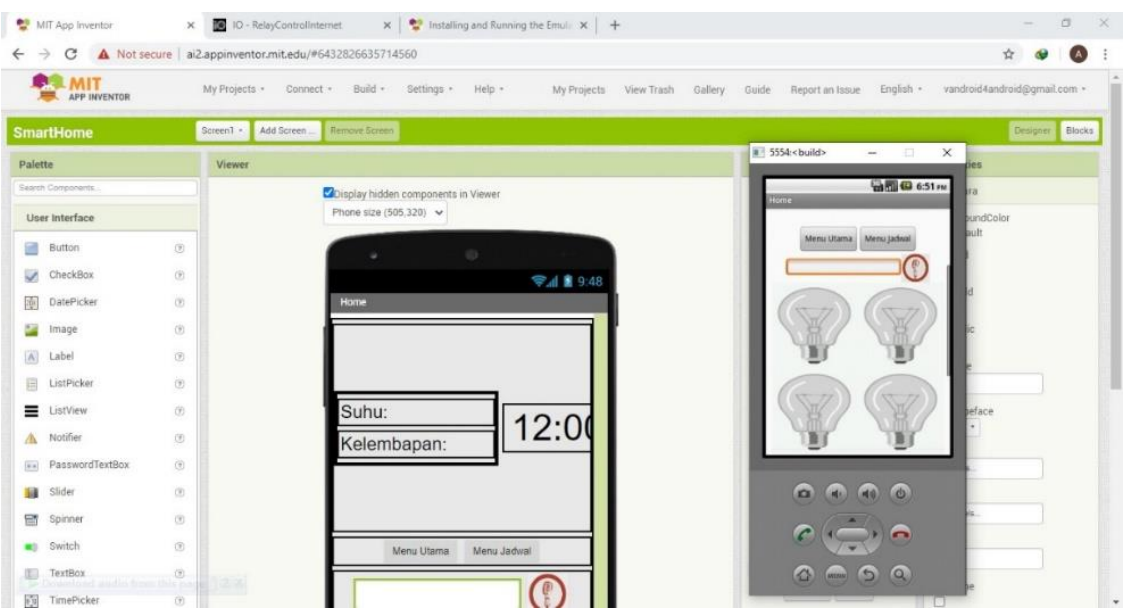

Gambar 8. Tampilan Ujicoba Aplikasi Via On Screen Emulator 
Pengujian prototipe sistem dilakukan untuk mengetahui berhasil atau tidaknya sebuah sistem yang telah dirancang apakah sesuai dengan apa yang telah dirancang atau tidak, apakah berfungsi dengan baik atau tidak. Dari hasil pengujian dapat diketahui kelemahan dan kekurangan yang masih terdapat pada alat, sehingga hasil perancangan perangkat keras (hardware) maupun perangkat lunak (software) dapat lebih disempurnakan untuk tujuan dan pemanfaatan secara nyata. Dimulai dari rancangan catu daya yang bermula dari adaptor $12 \mathrm{Vdc}$, kinerja dari mikrokontroler Wemos Lolin ESP-32, Relay, serta modul dan sensor yang akan digunakan.

Pada tahap ini juga dilakukan pengujian terhadap aplikasi berbasis android yang dibuat untuk menjadi user interface guna mempermudah user dalam mengontrol dan memonitor peralatan elektronik yang digunakan.

Di bawah ini merupakan data hasil pengujian fungsi pada tombol didalam aplikasi yang berfungsi sebagai saklar.

Tabel 1. Hasil Pengujian Tombol Saklar Didalam Aplikasi

\begin{tabular}{|c|c|c|c|c|}
\hline No & $\begin{array}{c}\text { Input } \\
\text { Tombol }\end{array}$ & Output Tombol & Status & Keterangan \\
\hline \multirow{2}{*}{1} & \multirow{2}{*}{ Lampu 1} & Icon Lampu Mati & OFF & Sesuai \\
\hline & & Icon Lampu Hidup & $\mathrm{ON}$ & Sesuai \\
\hline \multirow{2}{*}{2} & \multirow{2}{*}{ Lampu 2} & Icon Lampu Mati & OFF & Sesuai \\
\hline & & Icon Lampu Hidup & ON & Sesuai \\
\hline \multirow{2}{*}{3} & \multirow{2}{*}{ Kipas } & Icon Kipas Mati & OFF & Sesuai \\
\hline & & Icon Kipas Hidup & $\mathrm{ON}$ & Sesuai \\
\hline \multirow[b]{2}{*}{4} & \multirow[b]{2}{*}{ Kunci Pintu } & Icon Terkunci & OFF & Sesuai \\
\hline & & $\begin{array}{c}\text { Icon Tidak } \\
\text { Terkunci }\end{array}$ & ON & Sesuai \\
\hline
\end{tabular}

Di bawah ini merupakan data hasil pengujian fungsi perinta suara didalam aplikasi yang berfungsi sebagai saklar. 
Tabel 2. Hasil Pengujian Perintah Suara Pada Aplikasi

\begin{tabular}{|c|c|c|c|c|c|}
\hline No & Perangkat & Input Suara & Output Suara & Status & Keterangan \\
\hline \multirow{2}{*}{1} & \multirow{2}{*}{ Lampu 1} & $\begin{array}{c}\text { Hidupkan lampu } \\
\text { kamar }\end{array}$ & $\begin{array}{l}\text { Ok. Lampu kamar } \\
\text { akan dihidupkan }\end{array}$ & $\mathrm{ON}$ & Sesuai \\
\hline & & $\begin{array}{c}\text { Matikan lampu } \\
\text { kamar }\end{array}$ & $\begin{array}{l}\text { Ok. Lampu kamar } \\
\text { akan dimatikan }\end{array}$ & OFF & Sesuai \\
\hline \multirow{2}{*}{2} & \multirow{2}{*}{ Lampu 2} & $\begin{array}{l}\text { Hidupkan lampu } \\
\text { ruang tamu }\end{array}$ & $\begin{array}{l}\text { Ok. Lampu ruang } \\
\text { tamu akan } \\
\text { dihidupkan }\end{array}$ & $\mathrm{ON}$ & Sesuai \\
\hline & & $\begin{array}{l}\text { Matikan lampu } \\
\text { ruang tamu }\end{array}$ & $\begin{array}{l}\text { Ok. Lampu ruang } \\
\text { tamu akan } \\
\text { dimatikan }\end{array}$ & $\mathrm{OFF}$ & Sesuai \\
\hline \multirow{2}{*}{3} & \multirow{2}{*}{ Kipas } & $\begin{array}{l}\text { Hidupkan kipas } \\
\text { angin }\end{array}$ & $\begin{array}{l}\text { Ok. Kipas angin } \\
\text { akan dihidupkan }\end{array}$ & $\mathrm{ON}$ & Sesuai \\
\hline & & $\begin{array}{l}\text { Matikan kipas } \\
\text { angin }\end{array}$ & $\begin{array}{l}\text { Ok. Kipas angin } \\
\text { akan dimatikan }\end{array}$ & OFF & Sesuai \\
\hline \multirow{2}{*}{4} & \multirow{2}{*}{$\begin{array}{l}\text { Kunci } \\
\text { Pintu }\end{array}$} & Kunci pintu & $\begin{array}{l}\text { Ok. Pintu akan } \\
\text { dikunci }\end{array}$ & OFF & Sesuai \\
\hline & & $\begin{array}{l}\text { Buka kunci } \\
\text { pintu }\end{array}$ & $\begin{array}{l}\text { Ok. Pintu akan } \\
\text { dibuka }\end{array}$ & $\mathrm{ON}$ & Sesuai \\
\hline
\end{tabular}

Perintah suara menggunakan aplikasi Google Assistant dapat mempermudah user dalam memberikan perintah suara tanpa harus masuk kedalam aplikasi yang dibuat. Hanya perlu mengucapkan Ok Google lalu dilanjutkan dengan ucapan perintah yang berfungsi sebagai key untuk men-trigger sistem agar beraksi sesuai perintah.

Di bawah ini merupakan data hasil pengujian fungsi perintah suara menggunakan aplikasi Google Assistant yang berfungsi sebagai saklar.

Tabel 3. Hasil Pengujian Perintah Suara Menggunakan Google Assistant

\begin{tabular}{|c|c|c|c|c|c|}
\hline No & Perangkat & Input Suara & Output Suara & Status & Keterangan \\
\hline \multirow{2}{*}{1} & \multirow{2}{*}{ Lampu 1} & $\begin{array}{c}\text { Turn on the } \\
\text { bedroom light }\end{array}$ & $\begin{array}{l}\text { Ok. I Will Turn ON } \\
\text { The Bedroom Light. }\end{array}$ & ON & Sesuai \\
\hline & & $\begin{array}{c}\text { Turn off the } \\
\text { bedroom light }\end{array}$ & $\begin{array}{l}\text { Ok. I Will Turn OFF } \\
\text { The Bedroom Light. }\end{array}$ & OFF & Sesuai \\
\hline \multirow{2}{*}{2} & \multirow{2}{*}{ Lampu 2} & $\begin{array}{l}\text { Turn on the guest } \\
\text { room light }\end{array}$ & $\begin{array}{c}\text { Ok. I Will Turn ON } \\
\text { The Guest Room } \\
\text { Light. }\end{array}$ & $\mathrm{ON}$ & Sesuai \\
\hline & & $\begin{array}{l}\text { Turn off the guest } \\
\text { room light }\end{array}$ & $\begin{array}{l}\text { Ok. I Will Turn OFF } \\
\text { The Guest Room } \\
\text { Light. }\end{array}$ & OFF & Sesuai \\
\hline \multirow{2}{*}{3} & \multirow{2}{*}{ Kipas } & Turn on the fan & $\begin{array}{l}\text { Ok. I Will Turn ON } \\
\text { The Fan. }\end{array}$ & ON & Sesuai \\
\hline & & Turn off the fan & $\begin{array}{l}\text { Ok. I Will Turn OFF } \\
\text { The Fan. }\end{array}$ & OFF & Sesuai \\
\hline \multirow{2}{*}{4} & \multirow{2}{*}{ Kunci Pintu } & Lock the door & $\begin{array}{l}\text { Ok. I Will Lock The } \\
\text { Door. }\end{array}$ & OFF & Sesuai \\
\hline & & Unlock the door & $\begin{array}{l}\text { Ok. I Will Unlock } \\
\text { The Door }\end{array}$ & ON & Sesuai \\
\hline
\end{tabular}




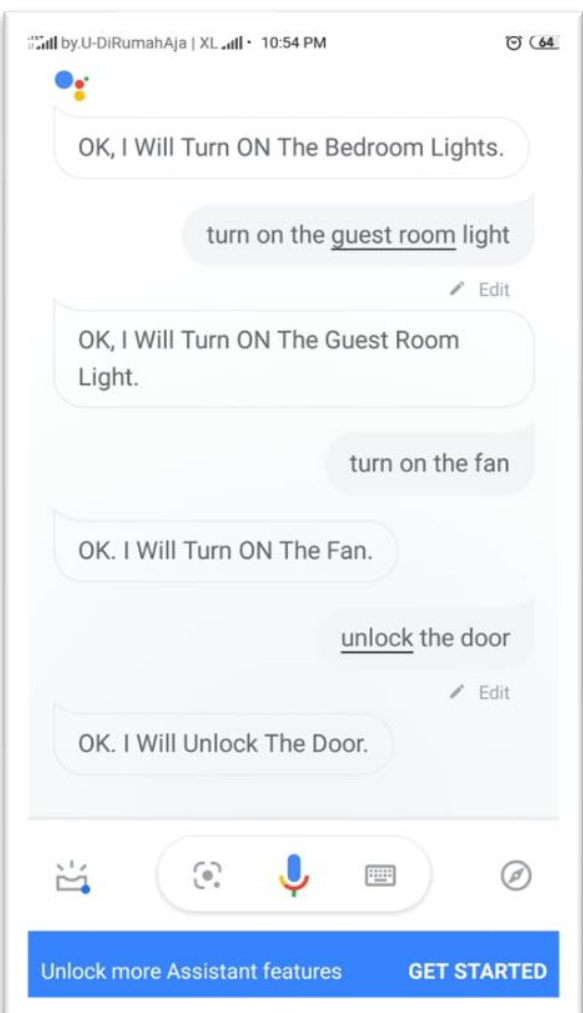

Gambar 9. Tampilan Pengujian Perintah Suara ON Menggunakan Google Assistant

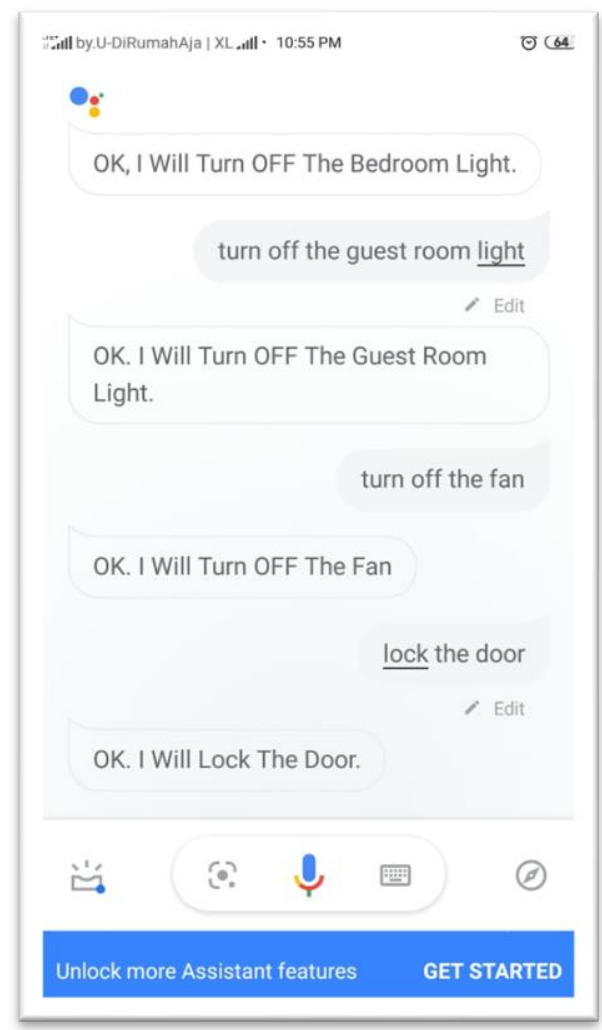

Gambar 10. Tampilan Pengujian Perintah Suara OFF Menggunakan Google Assistant 


\section{KESIMPULAN DAN REKOMENDASI}

Adapun kesimpulan yang dapat ditarik dari penelitian, perakitan hingga pengujian sistem Smarthome Dengan Konsep Internet of Things Berbasis Protokol Message Queuing Telemetry Transport ini adalah sebagai berikut :

Perancangan Sistem Smarthome Dengan Konsep Internet of Things Berbasis Protokol Message Queuing Telemetry Transport telah berhasil dibuat dan dapat dikendalikan kapan saja dan dimana saja menggunakan koneksi internet. Sistem ini berfungsi sebagaimana yang sudah dirancang dari awal yaitu dapat mempermudah user atau pemilik rumah dalam hal melakukan kendali jarak jauh dan monitoring peralatan elektronik yang digunakan menggunakan aplikasi berbasis android yang telah dikembangkan dan menggunakan aplikasi Google Assistant..

Sistem Smarthome ini dapat dikendalikan menggunakan perintah suara dengan bahasa Indonesia menggunakan aplikasi berbasis android yang telah dibuat atau menggunakan perintah suara dengan bahasa Inggris menggunakan aplikasi Google Assistant.

Berdasarkan penelitian yang telah dilakukan mengenai Perancangan Sistem Smarthome dengan konsep Internet of Things Berbasis Protokol Message Queuing Telemetry Transport, direkomendasikan sebagai berikut:

Penelitian selanjutnya dapat menambahkan perangkat yang dikendalikan menggunakan Mikrokontroler Wemos Lolin ESP-32 memiliki jumlah pin GPIO sebanyak 26 sehingga segala peralatan elektronik dapat dikendalikan dimana dan kapan saja.

Pada penelitian ini layanan akun web service yang digunakan bersifat terbatas atau lite service account, diharapkan penelitian selanjutnya dapat meningkatkan layanan menjadi full service account agar delay pada relay dapat di minimalisir.

Pada penelitian ini peralatan elektronik yang dapat dikendalikan masih bersifat statis. Pada penelitian selanjutnya agar bersifat dinamis sehingga dapat mengatur peralatan elektronik tanpa mengubah rangkaian kelistrikan. Pada penelitian selanjutnya diharapkan dapat menambah beberapa modul seperti kamera, servo serta beberapa sensor keamanan seperti smoke sensor dan PIR sensor agar dapat menunjang sistem smarthome. 


\section{REFERENSI}

Andri kuniyo \& kusrini (2007). Membangun sistem informasi akuntansi dengan visual basic \& sql server.

Eisenman, B. (2015). Learning react native: Building native mobile apps with JavaScript. " O'Reilly Media, Inc.".

Totok budioko (2016). Sistem monitoring suhu jarak jauh berbasis internet of things menggunakan protokol MQTT. Jurusan teknik komputer STIMIK AKAKOM Yogyakarta.

Trisiana, D. H., \& Indra, L. (2016). Rancang bangun saklar lampu otomatis dan monitoring suhu rumah menggunakan VB.Net dan Arduino. Jurnal teknologi rekayasa (2016:67-72).

Alfian, O. M., M. Firza. P., \& Julio, R. S. C., (2016). Sistem monitoring suhu dan kelembapan ruangan berbasis web. Sekolah tinggi teknik - PLN Jakarta.

Zulhipni, R. S., (2016). Perancangan monitoring suhu ruangan menggunakan arduino berbasis android di PT. Tunggal idaman abdi cabang palembang. JTI (2016:2).

Ichsan adisti, B. A., (2017). Monitoring suhu pemanas portable berbasis arduino yang terintegrasi dengan android. Jurusna teknik elektro Universitas Muhammadiyah Surakarta.

Borg and Gall (1983). Educational Research, An Introduction. New York and London. Longman inc.

Emizir. (2011). Metodologi penelitian pendidikan. Jakarta: Raja Grafindo Persada.

Gay, L.R. (1991). Educational Evaluation And Measurement: Com-petencies for analysis and application. Second edition. New York: Macmillan Publishing Company.

I Wayan Santyasa. (2009). Metode Penelitian Pengembangan \& Teori Pengembangan Modul. Makalah Disajikan dalam Pelatihan Bagi Para Guru TK, SD, SMP, SMA, dan SMK Tanggal 12-14 Januari 2009, Di Kecamatan Nusa Penida kabupaten Klungkung

Rita C. Richey, J. D. K., Wayne A. Nelson. (2009). Developmental Research : Studies of Instructional Design and Development.

Silvia, A. F., Haritman, E., \& Mulyadi, Y. (2014). Rancang Bangun Akses Kontrol Pintu Gerbang Berbasis Arduino Dan Android. Electrans, 13(1), 1-10.

Pressman, Roger S. 2005. Software Engineering. New York: McGraw Hill.

Ashton, Kevin. 2017. Making sense of IoT - How the Internet of Things became humanity's nervous systems. Hewlett Packard Enterprise. 
Yehuda, 2013, Purwarupa Sistem Rumah Cerdas Berbasis Arduino Uno yang Dikendalikan dengan Smartphone Android, Skripsi, Program Studi Elektronika Instrumentasi FMIPA UGM, Yogyakarta.

Yurmama S., T. F. dan Azman, N., 2009, Perancangan Software Aplikasi Pervasive Smart Home, Seminar Nasional Aplikasi Teknologi Informasi, Yogyakarta. 